\title{
MICHEL FOUCAULT: El funcionamiento de la institución escolar propio de la Modernidad
}

\section{MICHEL FOUCAULT: The functioning of the educational institution in Modern Society}

\author{
Mariano Urraco-Solanilla y Gema Nogales-Bermejo \\ Universidad de Extremadura \\ marianous@unex.es; gemmanogales54@hotmail.com
}

\section{Resumen:}

Este artículo contribuye a la comprensión del conocimiento existente sobre el funcionamiento del sistema educativo que ha caracterizado a la Modernidad. Nos apoyamos en el libro "Vigilar y Castigar" de Michel Foucault (1975) y de otros autores relevantes, anteriores y posteriores, sobre la misma cuestión.

La disciplina, el castigo, la docilidad, el control del tiempo, el examen, el diseño del espacio como ejercicio invisible del poder, son algunos de los conceptos claves que analizamos. Las conclusiones confirman que el acceso masivo a la educación proyectó individuos homogéneos, ni autónomos ni imaginativos. Lejos de los retos actuales de lograr una educación para la diversidad y la creatividad.

Palabras clave: Michel Foucault, disciplina, escuela, control, sistema educativo, poder invisible, examen

\begin{abstract}
:
This article contributes to the comprehension of existing knowledge on the functioning of the educational system that has characterized modern society. We rely on the book "Discipline and Punish" by Michel Foucault (1975) and works of other relevant authors, previous and later, dealing with the same subject.
\end{abstract}

Discipline, punishment, obedience, control of time, examination, and the design of the space as an invisible exercise of power are some of the key concepts that we analyze. The conclusions confirm that massive access to education projected the production of homogeneous individuals, neither autonomous nor imaginative. This is far from the current challenges of achieving an education that promotes diversity and creativity.

Keywords: Michel Foucault, discipline, school, control, educational system, invisible power, examination 


\section{Introducción}

Los conceptos innovadores aportados por Foucault en su análisis constituyen el hilo conductor de esta contribución. En una primera parte se analizan conceptos clave del sistema educativo como son el castigo, la docilidad y el control del tiempo. En una segunda parte se aborda la disciplina en tanto que estrategia para construir personas modernas a la par que homogéneas. En tercer lugar se analiza la función del examen. Y para terminar analizamos los elementos espaciales, del diseño de los lugares o centros educativos en tanto que ejercicio del poder invisible.

Profundizar en Foucault es una aportación al debate que sobre las mejoras del sistema educativo de los países occidentales nos lleva ocupando desde la crisis de los años ochenta, permitiéndonos visualizar las resistencias a reconfigurar ese mundo de relaciones entre profesores y alumnos en el que los primeros han ostentado el poder invisible durante largo tiempo.

Muchos son los libros recomendados en las distintas asignaturas que configuran un plan de estudios de cualquier carrera. Los programas están llenos de "bibliografía complementaria". Entre ese rubro interminable de "clásicos de referencia", la obra de Michel Foucault, "Vigilar y castigar" (publicada originalmente en 1975), ocupa un lugar preeminente entre los profesionales del ámbito educativo.

Nuestro propósito aquí es "desmenuzar" los distintos puntos de interés que tiene, para los profesionales de la escuela, un libro que, en principio, aborda el funcionamiento de las instituciones penales (de ahí el subtítulo: "nacimiento de la prisión"). Recorremos la senda de Foucault, conectando sus reflexiones con las aportaciones de otros autores, anteriores y posteriores a su obra. Un diálogo que permite aterrizar sobre la configuración de un mundo de realidad cotidiana: la Modernidad.

Así, analizamos el modo en que, a lo largo del texto de Foucault, se detallan ejemplos de procedimientos para dominar y manipular, así como las técnicas empleadas. Unas veces más o menos visibles, otras veces bajo la apariencia de bien común, pero todas buscando la instauración de la disciplina sin que parezca algo impuesto o que viene de fuera, sino como algo natural y necesario. Este proceso de "normalización" del poder será uno de los pilares sobre los que descansará el orden social moderno.

\section{Del castigo del alma, la docilidad y el control del tiempo}

Para Foucault el castigo al cuerpo ha sido sustituido por castigar al alma. Este castigo ya no se ejerce de manera directa sobre el cuerpo de los individuos, sino que se despliega de manera sutil por parte de una serie de especialistas (ya sean internos o externos) que juzgan, ponen etiquetas, toman decisiones.

Al "extrapolar" este enfoque al análisis de la institución escolar, en la que el castigo se equipara al trabajo con el alumnado llevado a cabo por parte de especialistas tales como psiquiatras, psicólogos, educadores. Convirtiéndose éstos en jueces, evaluadores, "verdugos" y agentes de dominación; instrumentos al servicio de un poder que sobrevuela la existencia de los individuos.

Un poder que "se ejerce sobre niños, colegiales, sobre aquellos a quienes se sujeta a un aparato de producción y se controla a lo largo de toda su existencia" (Foucault, 1992:36). Esta cita, y el tono general de algunos fragmentos de la obra de Foucault, permite enlazar con las teorías de Bowles y Gintis, o de Willis, así como con la noción de "currículum oculto", planteada por Illich. 
Pero ¿por qué el castigo se ha considerado, tanto en su génesis como en su evolución, como algo natural? Porque quienes ejercen el poder han convertido el derecho a castigar en una defensa de la sociedad, una corrección orientada a reformar, a curar, a "volver bueno" al desdichado. El castigo se presenta como algo inextricablemente unido a la propia naturaleza humana, a la necesidad imperiosa de corregir, de "normalizar"1.

\subsection{Seres útiles: la docilidad y el reglamento}

Aunque ese castigo se realice de forma sutil, no deja de tomar al cuerpo como objeto y blanco de poder al que se manipula, educa, da forma, domina... con el objetivo de producir seres útiles. Requisito imprescindible y a la vez consecuencia de este procedimiento de castigo (y de moldeamiento, en términos más generales) es el desarrollo de una serie de rasgos de carácter de los cuales el principal es la docilidad, la obediencia, la sumisión: sobre cuerpos sumisos se construyen futuros útiles.

Foucault nos remite al libro del Hombre-máquina, en el que La Mettrie (1748/2000) señala que un requisito para el surgimiento del individuo-máquina (que evoca con fragmentos de la Metrópolis de Von Harbou, 1926/1985) es la existencia de un organismo técnico-político. "Constituido por un conjunto de reglamentos militares, escolares, hospitalarios y por procedimientos empíricos y reflexivos para controlar o corregir las operaciones del cuerpo. En libro predomina la noción de "docilidad" que une al cuerpo analizable el cuerpo manipulable. Dócil es un cuerpo que puede ser sometido, que puede ser utilizado, que puede ser transformado y perfeccionado" (Foucault, 1992:140).

Para alcanzar estas características es necesaria la existencia de un régimen disciplinario que aumente habilidades útiles y fabrique cuerpos sometidos, ejercitados, dóciles, a través de la creación de vínculos de coacción mediante técnicas minuciosas ("microfísica del poder", en la terminología foucaultiana) llevadas a cabo en escuelas elementales, colegios... Es una "anatomía política del detalle", usada tanto en la pedagogía escolar como en la propia formación del ciudadano (del soldado, del obrero, del consumidor, del devoto...), que pone el énfasis en los aparentemente nimios elementos. "Técnicas minuciosas siempre, con frecuencia ínfimas" (Foucault, 1992:142) en que se puede descomponer la actuación escolar, pero de importancia, ya que servirán para encauzar conductas, además de sustentar y posibilitar la creación de reglamentos minuciosos que construyen una racionalidad económica o técnica.

Con Foucault debemos entender la disciplina como "una anatomía política del detalle" (Foucault, 1992:143), en el ámbito de la pedagogía escolar, como forma de encauzamiento de la conducta. Pone especial énfasis en las pequeñas cosas, en su observación (y observancia) para el control y la utilización de los hombres a través de "la minucia de los reglamentos, la mirada puntillosa de las inspecciones, la sujeción a control de las menores partículas de la vida y del cuerpo..." (Foucault, 1992:144).

El análisis de Foucault se aproxima asi a las tesis clásicas de Weber sobre la racionalidad y la racionalización, por más que el autor francés carga las tintas sobre el establecimiento, más o menos evidente, de un régimen disciplinario, sobre el que se basaría el sistema burocrático, pilar básico de la Modernidad.

1 En la trigésima y última lámina incluida a modo de anexo en el libro de Foucault, un dibujo de Andry fechado en 1749 sobre un joven árbol torcido, atado a un "tutor" que le guiará hasta convertirle en un sólido adulto (la metáfora arbórea, tan cara a la pedagogía clásica). 
Hablar de disciplina nos lleva a hablar, en primera instancia, de distribución de individuos en espacios. Y, como exigencia de esta disciplina espacial, un riguroso control del espacio (mas adelante veremos que el control se extiende a la otra dimensión: el tiempo). De manera que se impone el establecimiento de técnicas que Foucault resume como las siguientes.

La clausura, que queda ejemplificada, a nivel educativo, en el internado ${ }^{2}$. Otra de las técnicas empleadas en el control del espacio ${ }^{3}$ aplica el principio de localización elemental o de la división en zonas. Similar a esa técnica, se mencionan en el libro los emplazamientos funcionales. Estos responden no sólo a la necesidad de vigilar, de romper las comunicaciones peligrosas, sino también de crear espacio útil (después abordaremos el modelo panóptico de Bentham, presente a lo largo de toda la obra de Foucault).

Además, todo individuo figura en un registro (expediente) y, junto con la disposición en serie, en este caso de las aulas (disposición en cuadro como técnica de poder y dominación -imponer un orden). Ello permite vigilar, controlar, supervisar y posibilitar el trabajo simultáneo de todos los alumnos, fomentar la obediencia del individuo, establecer una economía del tiempo. Hablar de disposición en serie nos lleva a hablar de rango, entendido éste como el lugar que se ocupa en una clasificación: clases homogéneas, alineamientos por grupos de edad, sucesión de materias enseñadas... cada alumno ocupa un lugar según su jerarquía de saber y capacidad.

La comparación estará omnipresente en la vida de los individuos, y no sólo en el período escolar. Nuestras vidas, como dirá después Bauman (2005/2006) en su análisis de la postModernidad, se basan en un sistema de mediciones relativas, de permanente comparación de unos individuos entre sí y con respecto a un modelo o ideal, individuos que tienden a verse reducidos a productos en un gran escaparate de consumo y producción.

\subsection{Noción del tiempo}

Respecto al control de la actividad nos encontramos ante una noción clave en la obra de Foucault como es la noción del tiempo. La actividad temporal se encuentra también dispuesta en "series" sucesivas. Cuando hacemos alusión al empleo del tiempo, estamos refiriéndonos a la importancia de asegurar la calidad del tiempo empleado: estableciendo ritmos, regulando los ciclos de repetición.

"Toda una fiscalización de la duración por parte del poder: posibilidad de control detallado y de una intervención puntual -de diferenciación, de corrección, de depuración, de eliminación- en cada momento del tiempo; posibilidad de carácter, y por lo tanto de utilizar a los individuos según el nivel que tienen en las series que recorren" (Foucault, 1992:164).

Si hablamos de tiempo disciplinario hablamos de una serie de virtudes como son: regularidad, exactitud, puntualidad, premura... todas ellas reflejadas en el horario escolar (y en la vida monacal, tomada aquí por nuestro autor como ejemplo de la forma prístina de control del tiempo). En estos elementos encontramos reflejo de la definición de los rasgos de la burocracia planteados por Weber y que Ritzer (1993/1996)

2 La obra de Goffman (1961/1988) de título análogo, podría servirnos de enlace aquí, también porque este autor se centra, aparentemente, en instituciones -totales- de otro tipo, psiquiátricas, como epítome de la Modernidad y del triunfo de las lógicas despersonalizadoras.

3 Sobre el uso social del espacio, puede analizarse la propia obra de Goffman (1959/2006), a partir de Simmel, o los desarrollos del interaccionismo simbólico, entre los que se podría incluir la propia proxémica de Hall (1966/1973) o Sommer (1969/1974). 
"actualizará" posteriormente en su análisis de la sociedad moderna, en su famosa obra "La mcdonalización de la sociedad"4

El tiempo disciplinario se impone a la práctica pedagógica, especializando, calificando, dando lugar a una pedagogía analítica, muy minuciosa en su detalle. El poder se ejerce directamente sobre el tiempo y se asegura así su control y garantiza su uso. En este aspecto, el análisis de Foucault recuerda al marxista y muestra proximidad con las teorías de la correspondencia en Bowles y Gintis (1976/1985). Para éstos últimos la escuela no deja de ser un entrenamiento para el mundo capitalista.

El poder crea así individuos (y/o sujetos) y ese proceso requiere un control, un dominio y administración del tiempo. El reloj es invento del capitalismo. Lo vincula Koestler (1941/2001) en "El cero y el infinito", obra en la cual relaciona el capitalismo con la invención y la apropiación correlativa del tiempo, que se realizaba a través de diversos mecanismos que después serían ampliamente explotados en el fordismo, el taylorismo y demás precursores de la macdonalización. El cronómetro, símbolo del nacimiento del capitalismo, tal como indicaba Mumford, para conseguir individuos útiles y productivos, para favorecer así el progreso de las sociedades.

Con la sacrosanta alusión al progreso, todos los programas totalitarios han mostrado la necesidad de controlar el tiempo "libre" de los individuos, so pena de permitir (o aun fomentar) el vicio y el libertinaje (el refranero - los propios libros de texto contienen alusiones a lo pernicioso del tiempo libre.... El dictador Hitler, en sus "Principios de acción", aludía también a la necesidad de ocupar el tiempo de los individuos, de manera que nunca se hallasen ociosos (véase, sobre este particular, el análisis de Michaud, 1995/1996).

El foco de atención sobre el que se ejerce el control del tiempo es el ejercicio.

"procedimiento que está en el centro de esta seriación del tiempo y que es la técnica por la cual se imponen a los cuerpos tareas a la vez repetitivas y diferentes, pero siempre graduadas (...) permite una perpetua caracterización del individuo (...) Así garantiza, en la forma de continuidad y de la coerción, un crecimiento, una observación, una calificación" (Foucault, 1992:165).

Y ese ejercicio es entendido en el ámbito académico como programa escolar, como forma disciplinaria, pues se convierte en tecnología política del cuerpo y de la duración al ejercer el poder sobre las personas por medio de la distribución del tiempo, enmarcando todas las actividades en un calendario y en un horario detallado que encamina a los individuos a una subordinación perpetua ${ }^{5}$.

Razones económicas o de diferente índole han llegado a configurar un sistema de composición de fuerzas en el que la disciplina ha dado respuesta a las necesidades estructurales del sistema social vigente.

4 Para una defensa de esa sociedad macdonalizada, puede consultarse la obra de Heath y Potter (2004/2005), donde se cuestiona la paradoja en la que, según estos autores, incurre Ritzer al defender la igualdad y arengar a las masas lobotomizadas a una rebeldía en aras del comportamiento supuestamente aleatorio e impredecible.

5 Todo ello sin necesidad de hacer alusión al ejercicio meramente "físico", también presente desde sus orígenes en los sistemas educativos. Como refleja Viñao (2002) cuando comenta el modelo organizativo ideado por los Hermanos de la Vida Común, a los que también alude Foucault sobre este mismo tema. 
"la disciplina no es simplemente un arte de distribuir cuerpos, de extraer de ellos y de acumular tiempo, sino de componer unas fuerzas para obtener un aparato eficaz, esta exigencia se traduce de diversas maneras" (Foucault, 1992:168).

Y por ello es necesario matizar una serie de aspectos en el cambio histórico que sustenta esta nueva era.

Concepción del cuerpo.- El primero de ellos hace alusión a la concepción que del cuerpo se tiene: "...Ahora se concibe el cuerpo como una pieza de máquina multisegmentaria (...) el cuerpo singular se convierte en un elemento que se puede colocar, mover, articular sobre otros. Su arrojo o su fuerza no son ya las variables principales que lo definen, sino el lugar que ocupa, el intervalo que cubre, la regularidad, el orden según los cuales lleva a cabo sus desplazamientos" (Foucault, 1992:168-169).

La disciplina.- En segundo lugar Foucault menciona cómo la disciplina debe encargarse de combinar las series cronológicas pues así es como se obtiene el mayor provecho en términos de logro: "el tiempo de uno debe ajustarse al tiempo del otro de manera que la cantidad máxima de fuerzas pueda ser extraída de cada cual y combinada en un resultado óptimo" (Foucault, 1992:169). Con ello vemos cómo la organización/sistema escolar queda sujeta a una estandarización, a un modelo, no sólo a nivel arquitectónico (panóptico) sino también a nivel cronométrico y cronológico temporal.

Relación de señalización.- Como último matiz señalamos las características que ha de tener la actividad llevada a cabo por el individuo dominado: “... debe ser ritmada y sostenida por órdenes del profesor, cuya eficacia reposa en la brevedad y la claridad"

(Foucault, 1992:170, la cursiva es nuestra). Para que esta técnica surta efecto (control del comportamiento), es necesario que entre el profesorado y el alumnado se establezca un tipo de relación específica. Hablamos pues, de una relación de señalización, donde el maestro pone la disciplina a su sometido a través de señales tales como órdenes verbales, o acciones (como escribir en pizarra, sonidos de timbre...).

"El alumno deberá haber aprendido el código de las señales y responder automáticamente a cada una de ellas" (Foucault, 1992:170). El aprendizaje de estos símbolos, como la asimilación del conjunto de elementos que componen la subcultura escolar, es objeto recurrente de estudio, como muestra la etnografía clásica de Paul Willis (1977/1988) o la más reciente de Ángel Díaz de Rada (1996).

\section{La disciplina: modernos homogéneos}

Los aspectos mencionados con anterioridad ponen de manifiesto el modo en que la disciplina fabrica una individualidad. Se trata de una nueva concepción del ser humano, originada en la Modernidad, en la cual descansa y a la cual retroalimenta. Presenta las cuatro características siguientes, según manifiesta Foucault:

"es celular (por el juego de la distribución espacial), es orgánica (por el cifrado de las actividades), es genética (por la acumulación del tiempo), es combinatoria (por la composición de fuerzas)". Y para ello la disciplina se aplica mediante cuatro grandes técnicas: "construye cuadros [distribución]; prescribe maniobras; impone ejercicios; en fin, para garantizar la combinación de fuerzas, dispone "tácticas" [señales] (...) [siendo esta última] la forma más elevada de práctica disciplinaria" (Foucault, 1992:172). 
En su conjunto las prácticas disciplinarias conforman la docilidad automática, la subordinación, las coerciones continuadas (tanto individuales como colectivas), la educación y la formación indefinidamente progresivas y, por lo mismo, interminables, asintóticas, inalcanzables, tantálicas.

\subsection{La vigilancia}

El poder disciplinario, cuyo instrumento/procedimiento específico es el examen, desempeña la función principal de enderezar conductas. Para ello hace uso de instrumentos en principio muy simples: la inspección jerárquica, la sanción normalizadora y el propio examen. Es decir para poder ejercer este poder disciplinario se hace necesario activar un dispositivo de vigilancia jerárquica. Consiste en coacción por el juego de la mirada, unas miradas que deben ver sin ser vistas... Lo cual requerirá además de una arquitectura específica de "observatorio" para llevar un control interior, articulado y detallado.

En dicho sentido, la escuela deviene edificio operador de encauzamiento de conducta, aparato de vigilar, institución disciplinaria convertida en máquina de control que funciona como microscopio de la conducta:

"un punto central sería a la vez fuente de luz que iluminaría todo, y lugar de convergencia para todo lo que debe ser sabido: ojo perfecto al cual nada se sustrae y centro hacia el cual están vueltas todas las miradas" (Foucault, 1992:178).

Como en las pesadillas distópicas de Orwell (1949/2003), Zamiatin (1920/1991), o Levin (1970/1989), en la pecera de la vida social (y escolar), en el modelo panóptico de Bentham, nada escapa al ojo interesado. Ojo que, como demuestran los análisis de Illich (1971/1978) o Bourdieu y Passeron (1970/1981), para quienes la escuela juega un rol fundamental de "custodia", a modo de centro de concentración e internamiento; fija su mirada a través de los individuos durante una parte nada desdeñable del conjunto de horas de su infancia-juventud.

Más tarde y fruto de toda esta revolución, a las funciones de vigilancia se les incorpora un papel pedagógico, haciendo que queden integrados "en el interior de un dispositivo único tres procedimientos: la enseñanza propiamente dicha, la adquisición de conocimientos por el ejercicio mismo de la actividad pedagógica, y finalmente una observación recíproca y jerarquizada" (Foucault, 1992:181).

Esa observación recíproca y jerarquizada, vigilancia discreta, continua y global que reposa sobre individuos identificados y concretizados, se extendió en la Modernidad a múltiples instituciones, debido a la importancia de las nuevas mecánicas de poder que lleva consigo. Son mecánicas que se asientan en instituciones de larga tradición (el monasterio, el ejército, la escuela...), cuyo recorrido e historia traza el libro de Foucault para hacer descansar en ella el devenir de las sociedades modernas. Consiste en un ejercicio del poder disciplinario que puede ser a la vez absolutamente "indiscreto" (ya que está por doquier y siempre alerta) y absolutamente "discreto" (ya que funciona permanentemente y en una buena parte en silencio).

Acerca de estas mecánicas de poder permanente y continuo (todo el día, a lo largo de todos los días...), el antropólogo Kluckhohn (1966) hizo suyo un viejo proverbio norteamericano, que dice que es muy complicado que un pez se haga consciente de la existencia del agua. Pero no por ello el agua deja de existir, sino que, todo lo contrario, le rodea por todas partes. El ideal de celda presidiaria del que habla Foucault es la jaula de cristal en la que el individuo pueda estar vigilado en todo momento (en lo potencial infunde el temor para el autocontrol). 
Con el tiempo, el individuo, como el Prometeo de una de las leyendas kafkianas, puede olvidar que vive en una jaula (como el estudiante en un aula), y, como el pez en la pecera, descuidar la presencia del poder a su alrededor. A este respecto Weber hablaba de una jaula de hierro que Ritzer convertiría después en una jaula de goma o de suave terciopelo...

\subsection{La infrapenalidad}

Al hablar de sistemas disciplinarios se impone hacer referencia a ese pequeño, aparentemente modesto, mecanismo penal que todo lo ocupa, del que nada se abstrae, que todo lo "rellena" con una insidiosa "infra-penalidad" que penaliza y vigila las partículas más pequeñas de las conductas de los individuos.

"Reticulan un espacio que las leyes dejan vacío; califican y reprimen un conjunto de conductas que su relativa indiferencia hacía sustraerse a los grandes sistemas de castigo" (Foucault, 1992:183).

Si nos referimos al ámbito académico, vemos cómo “...en la escuela (...), reina una verdadera micropenalidad del tiempo (retrasos, ausencias, interrupciones de tareas), de la actividad (falta de atención, descuido, falta de celo), de la manera de ser (descortesía, desobediencia), de la palabra (charla, insolencia), del cuerpo (actitudes "incorrectas", gestos impertinentes, suciedad)..." (Foucault, 1992:183).

La disciplina contiene así una manera específica de castigar "es punible el dominio indefinido de lo no conforme (...) la "falta" del alumno, es, tanto como un delito menor, una ineptitud para cumplir sus tareas" (Foucault, 1992:182).

Vemos, por lo tanto, como el castigo es entendido como elemento correctivo, como instrumento de re-educación, en el que el efecto de cambio tiene un propósito que Foucault sintetiza en una noción clave: "encauzar", enderezar conductas desviadas. Tomando como accesorio el arrepentimiento o la expiación de los "errores" y las faltas.

"Castigar es ejercitar" (Foucault, 1992:185). Es repetir, como por ejemplo con los cursos "no aprovechados lo suficiente". Ese ejercicio del castigo, esa praxis de la disciplina, hace uso de un sistema doble de gratificación-sanción, como consecuencia del cual podremos cuantificar (a través de la penalidad tenemos conocimiento de los individuos, separados, divisibles en secuencias, en espacios, en registros... en casos) y cualificar (siempre la cualificación: lo bueno y lo malo, lo inteligente y lo torpe, lo sano y lo enfermo, lo moral y lo patológico... la dicotomía fundante sobre la que se construye nuestra concepción del mundo).

\subsection{Entre la jerarquización y la homogeneización}

Clasificar a los individuos y distribuirlos por rangos (cuantificación y cualificación) presenta una doble función: "señalar las desviaciones, jerarquizar las cualidades, las competencias y las aptitudes; pero también castigar y recompensar" (Foucault, 1992:186). Tomarán como referencia la clasificación reflejada en los informes, sobre "su conducta universalmente reconocida" (Foucault, 1992:186).

Lo universal, como tantas veces, vuelve a aparecer soslayando lo natural, el artificio definitivo, la maniobra de obliteración de lo que no deja de ser un constructo social. La inteligencia se usa en este caso, como medida objetiva y neutra, estándar pura y libre de pecado 6 .

6 Véase el estudio clásico de Beato y Villarino (1953/2004), y las críticas posteriormente recibidas por ambos médicos, para un necesario cuestionamiento de este tema. 
De manera que el fin de penalizar es que todos los individuos se asemejen, tiendan a parecerse, a actuar igual (se hagan previsibles, estimables en sus reacciones y respuestas), a homogeneizarse (a poder intercambiarse, pues, llegado el caso -la estandarización, la homogeneidad, el desvanecimiento de las diferencias entre individuos... Cuestión temida por Ritzer (1993/1996) y que celebran en cambio autores como Heath y Potter (2004/2005) como un triunfo de los ideales igualitarios que habrían acompañado al ser humano a lo largo de la Historia...).

Esta penalidad jerarquizante posee un doble efecto: de un lado la distribución de los individuos en tiempos y espacios, pero también en escalas y clasificaciones. Y de otro lado tiene el efecto de que ejerce sobre ellos una presión constante. Porque si el 1 y el 0 , el todo y la nada, se juntan en un modelo académico al que hay que tender, la presión es inevitable, en términos de desviación moral y estadística. Es decir, el procedimiento permite la comparación, jerarquización, homogeneización, exclusión. Una normalización aparejada a la desviación, la otra cara de la moneda (véase Matza, 1969/1981 y su maestro Howard Becker,1953).

"lo normal se establece como principio de coerción en la enseñanza con la instauración de una educación estandarizada y el establecimiento de las escuelas normales ${ }^{7 "}$ (Foucault, 1992:189)

En consecuencia, a partir de la vigilancia, con el uso de la técnica de jerarquía, y la normalización, con el uso de la técnica de sanción, pasamos a continuación a hablar del examen. Entendido como una observación que opera prolongando una justicia que se pretende objetiva. El examen también nos propicia analizar la relación existente, en éste, entre el poder y el saber llegando a convertirse en un instrumento que visibiliza, califica, clasifica, castiga, compara, mide, sanciona.

\section{El examen}

La función del examen para Foucault "establece sobre los individuos una visibilidad a través de la cual se los diferencia y se los sanciona. A esto se debe que, en todos los dispositivos de disciplina, el examen se halle altamente ritualizado. En él vienen a unirse la ceremonia del poder y la forma de la experiencia, el despliegue de la fuerza y el establecimiento de la verdad (...) la superposición de las relaciones de poder y de las relaciones de saber adquiere en el examen toda su notoriedad visible" (Foucault, 1992:185).

En el ámbito escolar irrumpe la figura del examen. Acompaña a los individuos también fuera de las puertas de la escuela, pero tiene en aquélla su campo semántico específico y "natural". "...la escuela pasa a ser una especie de aparato de examen ininterrumpido que acompaña en toda su longitud la operación de enseñanza (...) una comparación perpetua de cada cual con todos, que permite a la vez medir y sancionar (...)" (Foucault, 1992:185). Porque el examen en la Modernidad, además de sancionar un aprendizaje, es uno de sus factores permanentes, subyacentes, según un ritual de poder constantemente prorrogado.

Ahora bien, "el examen permite al maestro establecer sobre sus discípulos todo un campo de conocimientos (...). El examen en la escuela, crea un verdadero y constante intercambio de saberes. Garantiza el paso de los conocimientos del maestro al

7 La denominación que reciben las escuelas de profesorado, escuelas "Normales" no es trivial sino explícita de su finalidad normalizadora. 
discípulo, pero toma del discípulo un saber reservado y destinado al maestro. La escuela pasa a ser el lugar de elaboración de la pedagogía" (Foucault, 1992:185-191).

\subsection{De individuos a casos documentados}

Foucault destaca que el examen hace visible el ejercicio de poder por virtud del cual el alumno es objeto de la observación de un poder de manera indirecta. Este mismo individuo (súbdito sometido, alumno dócil y aplicado, buen ciudadano), a su vez, y por medio del examen, entra en un campo documental que va a proporcionar tanto el análisis y la descripción del alumno como la inserción de un sistema de comparación.

Weber (1913/1999), en su análisis de los literatos chinos, ya señalaba la función de reconocimiento, de identificación diferencial, del examen y las prácticas a él asociadas. Esta perspectiva entronca con la necesidad del tiempo "ocioso" en Veblen (1899/2004), o con el análisis de Bourdieu (1979/1991) sobre la "distinción" y sus formas de manifestarse, de hacerse visible, de encarnarse en capitales de diverso tipo, como el propio lenguaje (Bernstein, 1971/1989).

Gracias a estos procedimientos vinculados al examen (análisis, descripción, comparación) va a ser posible hacer del individuo un "caso" y por tanto se conceden así al poder mayores licencias, al hacer de la persona un individuo, y del individuo un caso, un ser descriptible, sobre el que habrá mayor facilidad (probabilidad) de ejercer una mayor dominación, un mayor control, llevándonos esto a las tan mencionadas prácticas de clasificación, distribución...

"Es el individuo tal como se le puede describir, juzgar, medir, comparar a otros y esto en su individualidad misma; y es también el individuo cuya conducta hay que encauzar o corregir, a quien hay que clasificar, normalizar, excluir, etcétera (...) El examen como fijación a la vez ritual y "científica" de las diferencias individuales, como adscripción de cada cual al rótulo de su propia singularidad (...) Indica la aparición de una modalidad nueva de poder en la que cada cual recibe como estatuto su propia individualidad, y en la que es estatutariamente vinculado a los rasgos, las medidas, los desvíos, las "notas" que lo caracterizan y hacen de él, de todos modos, un "caso" (...) Nos referimos al individuo entendido como un átomo ficticio de una representación "ideológica" de la sociedad; pero también una realidad fabricada por esa tecnología específica de poder que se llama "disciplina"” (Foucault, 1992:196-198 -nótese aquí la distinción terminológica, que no es menor, existente entre "sujeto" e "individuo", tan explotada por Jesús Ibáñez y su escuela sociológica).

La noción de "caso" es también habitual en la medicina moderna, que en el libro de Foucault aparece vinculada a la propia Modernidad, del mismo modo que lo está la pedagogía tradicional, en la que abundan los exámenes, los diagnósticos, la búsqueda de soluciones...

"Finalmente, el examen (...) es el que combinando la vigilancia jerárquica y sanción normalizadora, garantiza las grandes funciones disciplinarias de distribución y clasificación, de extracción máxima de las fuerzas y del tiempo, de acumulación genética continua, de composición óptima de las aptitudes (...) Con él se ritualizan esas disciplinas que se pueden caracterizar con una palabra diciendo que son una modalidad de poder para el que la diferencia individual es pertinente" (Foucault, 1992:197). 


\section{El modelo panóptico y la normalización}

Este desarrollo que constituye la escuela tiene lugar en un "marco" físico concreto (el frame en Goffman), a cuya descripción minuciosa Foucault dedica también importantes esfuerzos. El sistema arquitectónico panóptico tiene múltiples aplicaciones y es, seguramente, la parte más conocida del libro del autor francés. En términos escolares ha supuesto un dispositivo especialmente útil, constituyéndose en la "utopía del encierro perfecto" (Foucault, 1992:208) para, como ya se ha dicho, encauzar conductas, ejercer ese poder invisible y generalizado mediante mecanismos o dispositivos disciplinarios "escritos en la propia piedra", determinados por la distribución espacio-temporal que prescribe y establece.

Podemos, no obstante, encontrar una explicación menos "malvada" del desarrollo de esta arquitectura. "Por detrás de los dispositivos disciplinarios, se lee la obsesión de los "contagios", de la peste, de las revueltas, de los crímenes, de la vagancia, de las deserciones, de los individuos que aparecen y desaparecen, viven y mueren en el desorden. La imagen de la peste valió por todas las confusiones y desórdenes; del mismo modo que la imagen de la lepra, del contacto que cortar, se halla en el fondo de los esquemas de exclusión. Esquemas diferentes, pues, pero no incompatibles.

Corresponde al siglo XIX haber aplicado al espacio de la exclusión cuyo habitante simbólico era el leproso (y los mendigos, los vagabundos, los locos, los violentos, formaban su población real) la técnica de poder propia del reticulado disciplinario.

De manera general todas las instancias de control individual, funcionan de un doble modo: el de la división binaria y la marcación (loco-no loco; peligroso-inofensivo; normal-anormal); y el de la asignación coercitiva, de la distribución diferencial (quién es; dónde debe estar; porqué caracterizarlo, cómo reconocerlo; cómo ejercer sobre él, de manera individual, una vigilancia constante, etc.) . Los mecanismos de poder, todavía en la actualidad, se disponen en torno de lo anormal, tanto para marcarlo como para modificarlo (Foucault, 1992:201-203).

El panóptico de Bentham es la figura arquitectónica de la composición, que tiene como efecto mayor "inducir en el detenido un estado consciente y permanente de visibilidad que garantiza el funcionamiento automático del poder" (Foucault, 1992:204; Spradley, 1970).

Entre las consecuencias de dicha visibilidad encontramos la anulación de la colectividad, la toma de consciencia (y de conciencia) de los límites individuales, que la postModernidad tanto ha trabajado en marcar (el colectivo, las masas, siempre tan peligrosas -Le Bon, 1895/2005; Tarde, 1901/1986; McDougall, 1908; Ortega, 1930/2003...).

En esta obra arquitectónica están inmersos los mecanismos de poder, podemos apreciar cómo es posible el establecimiento de diferencias, tendiendo siempre hacia la modificación de comportamientos.

Aparentemente, este panóptico será accesible a todo el mundo "ahora se convierte en un edificio transparente [como la cocina de la hamburguesería o de las pizzerías] donde el ejercicio del poder es controlable por la sociedad entera" (Foucault, 1992:211), bajo la forma del bien común y de la defensa de los intereses de la mayoría.

Y que lo que pretende es su difusión en el cuerpo social "su vocación es volverse en él una función generalizable (...) se trata de volver más fuertes las fuerzas sociales 
-aumentar la producción, desarrollar la economía, difundir la instrucción, elevar el nivel de la moralidad pública; hacer crecer y multiplicar" (Foucault, 1992:211). Desde dicha perspectiva, se trata, pues, de una sociedad vigilante, en línea con los planteamientos de Ulrich Beck (1986/1998).

En síntesis, en la Modernidad asistimos al nacimiento de una nueva "anatomía política" cuyo fin es que se establezcan relaciones de disciplina: “...proyectar una institución disciplinaria perfecta. Pero se trata también de demostrar cómo se pueden "desencerrar" las disciplinas y hacerlas funcionar de manera difusa, múltiple, polivalente en el cuerpo social entero. Son disciplinas "que la época clásica elaborará en lugares precisos y relativamente cerrados -cuarteles, colegios, grandes talleres- y cuyo empleo global no se había imaginado sino a la escala limitada y provisional de una ciudad en estado de peste..." (Foucault, 1992:212).

Lo novedoso en el siglo XVIII es que la racionalidad científica traspasa el umbral "tecnológico" llegando así a la escuela como centro de producción de individuos. Se convierte así en mecanismo de objetivación que puede valerse como instrumento de sometimiento y aumento de poder que da lugar a más conocimientos, a un mayor dominio, a una mayor competencia. En este clima se gestaron ciencias tales como la psicología, la psicopedagogía (Foucault, 1992:228-230). Se pone de manifiesto cómo existe una unión indisoluble entre formación de poder y formación de saber y cómo se considera el siglo XVIII como el siglo en que se inventaron las técnicas de las disciplinas y del examen después perfeccionadas, pulimentadas, mejoradas. Las nuevas ciencias se pondrán al servicio de los objetivos educativos de la época.

En definitiva, el modelo citado impone una educación total donde el individuo se encuentra sometido a una "omnidisciplina", en la que el Estado dispone de manera total(izante) del tiempo (y del cuerpo) de una persona, y puede regularlo a voluntad, estableciendo ritmos, marcando espacios, fijando prácticas y repeticiones. Este régimen de vida se va a basar en una serie de principios, entre los que se destacarían el aislamiento y la comunicación unidireccional (es decir, la no-comunicación); el trabajo como elemento de evasión (y/o de realización personal), de creatividad, de fomento de la moralidad, de realización personal; y la lógica de modulación de penas, medibles, ponderables, equiparables a tiempos y a niveles de castigo.

\section{Conclusiones}

En síntesis, la obra "Vigilar y castigar" de Foucault se refiere al sistema educativo gestado en la Modernidad y se centra en los mecanismos empleados por el poder para hacerse natural y de cómo dicho poder se ejerce sobre los individuos en distintos ámbitos (político, religioso, escolar...) configurando un tipo concreto de consumidor, un tipo concreto de trabajador, un tipo concreto de ciudadano, un tipo concreto de estudiante y de profesional de la enseñanza...

En este trabajo hemos llevado a cabo un análisis pormenorizado de algunos elementos clave del pensamiento del autor francés, en la medida que nos permitían estudiar el funcionamiento de la institución escolar propia de la Modernidad y los principios por los que aquélla se rige.

Especial atención hemos dedicado nuestra atención a las nociones de poder, disciplina, distribución espacial, tiempo, sanción, examen, registro, vigilancia, castigo... 
Y es que el foco de atención del libro descansa en el proceso de "moldeamiento" (compuesto por toda esa multitud de prácticas) que experimentan los individuos internados en las instituciones sociales mediadas por el poder y configuradas por la Modernidad. Y ahí coinciden tanto la prisión como el hospital, como el psiquiátrico, como el taller o la fábrica, como la escuela y la universidad. Hablamos de vigilantes, de policías, jueces, celadores... o maestros y orientadores escolares.

Respecto al profesor de este régimen educativo moderno, cuyas funciones tradicionales son transmitir conocimientos, valores socialmente aceptados, establecer orden... aparece en Foucault como una figura de control, de "encauzamiento", de restricción de la libertad y la creatividad en aras de una normalización de los estudiantes puestos bajo su tutela.

Además, este "profesor a la Foucault", este modelo profesional del maestro generado en y con la Modernidad, tendría en el examen (por mencionar únicamente uno de los aspectos en los que se centra el autor francés al analizar la omnipresente disciplina inherente al sistema escolar, a su multiplicidad de prácticas orientadas a un mismo fin) una herramienta de control fundamental.

El examen (y la infinita sucesión de exámenes en distintas etapas, sobre distintas materias marcadas como "socialmente necesarias o adecuadas" y sancionadas en planes de estudio, currículos oficiales, etc.) va construyendo a los individuos, convirtiéndolos en casos aislados y aislables, generando comparaciones, generando registros (haciendo de las personas casos, expedientes), generando trampas y mecanismos de castigo para corregir (o reafirmar) esas conductas, deshonestas pero funcionales al sistema, por cuanto lo legitiman (si no hubiera vigilantes no habría fraude... si no hubiera fraude, no habría vigilantes).

El examen, sobre todo, marca una norma a la que todos los individuos están obligados a asimilarse y con respecto a la cual (el uno y el cero unidos, como ideal académico) habrían de intentar no "desviarse" (la media y la desviación típica como medidas recurrentes en el ámbito educativo moderno).

Esta visión "pesimista" del ámbito profesional es una idea a descartar aunque pueda estar ya presente en muchos estudiantes y profesores, sobre todo en los más proclives a confiar en teorías conspiratorias de mayor o menor alcance y profundidad. El propio Foucault finaliza su libro (un tanto abruptamente, mediante una nota al pie) señalando futuras guías de trabajo: "Interrumpo aquí este libro que debe servir de fondo histórico a diversos estudios sobre el poder de la normalización y la formación del saber en la sociedad moderna" (Foucault, 1992:314).

Tras Foucault la producción pedagógica alternativa ha sido incesante, empezando por autores de la denominada "Perspectiva comunicativa" (Freire, 1985/1990; Ayuste et al., 1994; McLaren y Kincheloe, 2007/2008), o la tradición desarrollada a partir de la Escuela de Frankfurt (Habermas). Tambien la obra de Michael Apple (1982/1997), de Henry Giroux (1992) y la Pedagogía Crítica de Wiggins (1998) son corrientes todas ellas que establecen un diálogo con Foucault y se esfuerzan por sentar las bases de un nuevo modelo de relaciones sociales en las aulas. Su análisis es una tarea que abordaremos en futuras publicaciones. 


\section{Bibliografía.}

Apple, M. W. (1982/1997). Educación y poder. Barcelona: Paidós.

Ayuste, A., Flecha, R., López Palma, F., y Lleras, J. (1994). Planteamientos de la pedagogía crítica: Comunicar y transformar. Barcelona: Graó.

Bauman, Z. (2005/2006). Vida líquida. Barcelona: Paidós.

Beato, V., y Villarino, R. (1953/2004). Capacidad mental del negro. En N. Fernández Moreno (Comp.), Temas de etnología regional (pp. 135-151). Madrid: UNED.

Beck, U. (1986/1998). La sociedad del riesgo: Hacia una nueva modernidad. Barcelona: Paidós.

Becker, H. S. (1953). Becoming a marihuana user. American Journal of Sociology, LIX, 3, 235-242.

Bernstein, B. B. (1971/1989). Clases, códigos y control. Madrid: Akal.

Bourdieu, P. (1979/1991). La distinción: Criterios y bases sociales del gusto. Madrid: Taurus.

Bourdieu, P., y Passeron, J. (1970/1981). La reproducción: Elementos para una teoría del sistema de enseñanza. Barcelona: Laia.

Bowles, S., y Gintis, H. (1976/1985). La instrucción escolar en la américa capitalista: La reforma educativa y las contradicciones de la vida económica. Madrid: Siglo XXI.

Díaz de Rada, Á. (1996). Los primeros de la clase y los últimos románticos: Una etnografía para la crítica de la visión instrumental de la enseñanza. Madrid: Siglo XXI.

Foucault, M. (1975/1992). Vigilar y castigar: Nacimiento de la prisión. Madrid: Siglo XXI.

Freire, P. (1985/1990). La naturaleza política de la educación: Cultura, poder y liberación. Barcelona: Paidós.

Giroux, H. A., y Flecha, R. (1992). Igualdad educativa y diferencia cultural. Barcelona: El Roure.

Goffman, E. (1959/2006). La presentación de la persona en la vida cotidiana. Buenos Aires: Amorrortu.

Goffman, E. (1961/1988). Internados: Ensayos sobre la situación social de los enfermos mentales. Buenos Aires: Amorrortu.

Hall, E. T. (1966/1973). La dimensión oculta: Enfoque antropológico del uso del espacio. Madrid: Instituto de Estudios de Administración Local.

Heath, J., y Potter, A. (2004/2005). Rebelarse vende: El negocio de la contracultura. Madrid: Taurus.

Illich, I. (1971/1978). La sociedad desescolarizada. Barcelona: Barral.

Kluckhohn, C. (1966) Initiation à I'anthropologie. Bruselas: Dessart.

Koestler, A. (1941/2001). El cero y el infinito. Barcelona: Círculo de lectores.

La Mettrie, J. O. (1748/2000). El hombre máquina; El arte de gozar. Madrid: Abraxas.

Le Bon, G. (1895/2005). Psicología de las masas. Madrid: Morata.

Levin, I. (1970/1989). Este día perfecto. Barcelona: Destino. 
Matza, D. (1969/1981). El proceso de desviación. Madrid: Taurus.

McDougall, W. (1908). An introduction to social psychology. Londres: Methuen.

McLaren, P., y Kincheloe, J. L. (Eds.). (2007/2008). Pedagogía crítica: De qué hablamos, dónde estamos. Barcelona: Graó.

Michaud, E. (1995/1996). "Soldados de una idea": Los jóvenes bajo el tercer reich. En G. Levi, y J. Schmitt (Dirs.), Historia de los jóvenes: II. la edad contemporánea (pp. 347380). Madrid: Taurus.

Ortega y Gasset, J. (1930/2003). La rebelión de las masas. Madrid: Tecnos.

Orwell, G. (1949/2003). 1984. Barcelona: Destino.

Ritzer, G. (1993/1996). La mcdonalización de la sociedad: Un análisis de la racionalización en la vida cotidiana. Barcelona: Ariel.

Sommer, R. (1969/1974). Espacio y comportamiento individual. Madrid: Instituto de Estudios de Administración Local.

Spradley, J. P. (1970). You owe yourself a drunk: An ethnography of urban nomads. Boston: Little, Brown \& Co.

Tarde, G. (1901/1986). La opinión y la multitud. Madrid: Taurus.

Veblen, T. (1899/2004). Teoría de la clase ociosa. México: Alianza.

Viñao Frago, A. (2002). Sistemas educativos, culturas escolares y reformas: Continuidades y cambio. Madrid: Morata.

Von Harbou, T. (1926/1985). Metrópolis. Barcelona: Orbis.

Weber, M. (1913/1999). Los literatos chinos. En M. Fernández Enguita (Ed.), Sociología de la educación (pp. 63-71). Barcelona: Ariel.

Wiggins, G. (1998). Educative assesment: Designing assesments to inform and improve student performance. San Francisco, CA: Jossey-Bass.

Willis, P. E. (1977/1988). Aprendiendo a trabajar: Cómo los chicos de la clase obrera consiguen trabajos de clase obrera. Madrid: Akal.

Zamiatin, E. I. (1920/1991). Nosotros. Barcelona: Tusquets. 